\title{
A metodologia de Max Weber entre reconstrução e desconstrução
}

\section{Max Weber's Methodology \\ Between Reconstruction And Deconstruction}

SÉRGIO DA MATA ${ }^{1}$ https://orcid.org/0000-0002-7963-6292

${ }^{1}$ Departamento de História

Universidade Federal de Ouro Preto

Rua do Seminário, s/n, Mariana, MG, 35.420-000, Brasil

sdmata@ufop.edu.br

Obra resenhada:

Max Weber Gesamtausgabe I/7. Zur Logik und Methodik der Sozialwissenschaften. Schriften 1900-1907. Org. Gerhard Wagner. Tübingen: Mohr Siebeck, 2018. 772p.

Max Weber morreu aos cinquenta e seis anos de idade, em 14 de junho de 1920. Dez anos depois, e apesar dos esforços de Karl Jaspers, Hans Freyer e Raymond Aron, eram poucos os eruditos alemães que ainda o mencionavam. Traduzido por mexicanos e norte-americanos, Weber atravessa o Atlântico e começa a ganhar a América, ao passo que na Alemanha nacional-socialista seus livros - compreensivelmente - juntavam poeira nas estantes. Essa longa hibernação só acaba em fins da década de 1950, quando fica clara a dívida da Escola de Frankfurt para com a tese weberiana da racionalização ocidental, e em especial com a publicação dos notáveis estudos de Wolfgang Mommsen, Reinhard Bendix e Friedrich Tenbruck. A partir de então já não era possível ler e

Recebido: 06 set.2019 | Aprovado: 28 set. 2019

http://dx.doi.org/10.1590/0104-87752020000100009

Varia Historia, Belo Horizonte, vol. 36, n. 70, p. 253-259, jan/abr 2020 
interpretar este clássico das ciências humanas sem o suporte de disciplinas como a história das ideias, e, não menos importante, sem recorrer a este imenso monumento de erudição que é a edição crítica das obras completas de Weber, a Max Weber Gesamtausgabe (MWG).

A editora Mohr Siebeck e Academia de Ciências da Baviera acabam de publicar o volume $\mathrm{I} / 7$, contendo a maior parte dos ensaios que se tornaram conhecidos no Brasil e outros países sob o título de "Metodologia das Ciências Sociais". O aparecimento deste livro de mais de 700 páginas, intitulado Sobre a lógica e a metodologia das ciências sociais. Escritos 1900-1907, pode ser considerado um evento editorial de grande importância. Isso vale igualmente para os historiadores, uma vez que é justamente nesse conjunto de textos que se encontra o essencial da teoria weberiana do conhecimento histórico.

Foi Marianne Weber quem coligiu, em 1922, os textos teórico-metodológicos publicados por seu marido entre 1903 e 1919, e que receberam o título um pouco pretensioso de Gesammelte Aufsätze zur Wissenschaftslehre, "Ensaios reunidos sobre doutrina da ciência". A história de sua recepção é atribulada, pois via de regra as primeiras traduções para o inglês, o francês, o italiano e o espanhol não incluíram a totalidade do material selecionado por Marianne. O pecado não chega a ser grande, já que o conjunto de textos que conteria o fundamental da epistemologia weberiana é ainda uma questão em aberto entre os especialistas. A edição alemã de 1922 passaria por alterações significativas em 1951 e 1968, com a inclusão de textos que a viúva de Weber não havia selecionado em 1922 (Sell, 2018, p.321-322). Assim, não pareceu impróprio aos responsáveis pela edição inglesa mais recente a inclusão de textos inéditos como o agora famoso "Manuscrito de Nervi", essencial para mensurar o peso da influência do filósofo Heinrich Rickert sobre Weber. Essa tumultuada história editorial está longe de terminar, uma vez que os editores da MWG optaram por uma solução que não chega a ser consensual: o conjunto de textos original foi cindido em duas partes, uma anterior e outra posterior ao biênio 1907-1908. Uma decisão que implica, literalmente, na implosão do volume organizado pela viúva de Weber. 
Tenbruck foi o primeiro a questionar publicamente o que chamou de "desmontagem" (Tenbruck, 1989, p.102). Mas não convém superestimar suas consequências. Para o bem e para o mal, as decisões tomadas pelos coordenadores da edição crítica só muito raramente têm sido acompanhadas pelas traduções de Weber ao redor do mundo, e não há razão para supor que nesse caso há de ser diferente. O que nos parece particularmente interessante aqui é o fato de que os dois volumes resultantes estavam entre os primeiros anunciados da MWG. O primeiro deles, objeto desta resenha, deveria ter aparecido em 1984; e o segundo para 1987. Você leu corretamente: três décadas e meia de atraso!

Segundo nos disse há pouco uma das pessoas diretamente envolvidas, o editor originalmente designado para o volume não conseguiu levar adiante o penoso processo de preparação dos textos, o que implicou uma perda de tempo que, de resto, já vitimara outros importantes volumes da MWG, entre eles o que contém os famosos artigos sobre "a ética protestante". Mas, independente das muitas possíveis razões envolvidas, tal lapso de tempo é eloquente o bastante, fala uma linguagem clara: não era uma prioridade disponibilizar ao público a edição histórico-crítica dos textos que sistematizam a concepção weberiana de ciência histórica e social.

Também na outra ponta há problemas. Trata-se de textos bastante desiguais em densidade analítica e em qualidade literária (alguns são inegavelmente prolixos), e cuja tradução impõe grandes dificuldades. Basta dizer que a versão brasileira (Weber, 2001), realizada em conjunto pelas editoras Unicamp e Cortez no início da década de 1990 (e atualmente em sua $5^{\text {a }}$ edição) está longe de ser adequada. Embora tenha sido deixada a cargo de um alemão radicado no Brasil, o falecido Augustin Wernet, é tal o número de erros ali cometido - de desvios terminológicos ao "sumiço" de parágrafos inteiros - que temos recomendado sempre o uso da criteriosa versão inglesa, traduzida por um dos maiores conhecedores deste corpus, o dinamarquês Hans Henrik Bruun (Weber, 2012).

Em que pesem tais dificuldades e o colossal atraso, Sobre a lógica e a metodologia das ciências sociais é um precioso instrumento de trabalho. 
De nossa parte, importa-nos sublinhar o seu valor para historiadores das ideias e interessados em teoria da história. Estes escritos, que contém o essencial da metodologia de Weber, são fruto de seu diálogo não apenas com clássicos como Ranke, Roscher e Droysen, mas também com os mais importantes nomes da teoria da história de inícios do século passado - de Dilthey a Simmel, de Rickert a Gottl. Seu objetivo é fundamentar a "ciência da realidade", assim definida:

A ciência social que nós pretendemos praticar é uma ciência da realidade. Queremos compreender a realidade da vida ao nosso redor, e na qual nos situamos, em sua especificidade - por um lado: as conexões e a relevância cultural de suas diversas manifestações em sua configuração atual, e, por outro, as causas pelas quais ela se desenvolveu historicamente de uma determinada maneira e não de outra (p.174).

Aqui se estabelece o programa do Arquivo para a Ciência Social e a Política Social, revista que Weber tinha assumido em 1903 em parceria com Werner Sombart e Edgar Jaffé. As diferenças em relação ao funcionalismo durkheimiano saltam aos olhos. Para Weber a prioridade epistêmica não são as recorrências, as "leis" ou os "modelos", mas os fenômenos singulares, considerados intersubjetivamente como relevantes. Vale dizer, "históricos". Mais ainda, a elucidação de tais fenômenos deve se dar diacronicamente, historicamente. Somente desta forma se chega a saber como eles se tornaram o que são. Um programa, enfim, que se afasta não só do modelo francês, mas também daquele furor taxonômico que se apodera do próprio Weber ao longo das páginas de Economia e Sociedade (Mata, 2019).

É incomum que numa resenha se fale tão pouco da obra em si, mas o leitor há de admitir que se trata de um caso à parte. Embora mal traduzidos ou traduzidos apenas em partes para o português, a maior parte do material que compõe o volume I/7 da MWG já está à disposição do público brasileiro na Metodologia das ciências sociais. O que se pode esperar de uma edição crítica, além do minucioso trabalho de depuração filológica próprio de empreendimentos desta envergadura 
é, por um lado, a apresentação de eventuais "descobertas" (manuscritos inéditos, versões alternativas aos textos já publicados, etc), e, por outro, novas interpretações obtidas à luz do material inédito. De fato, salvo por alguns fragmentos de menor importância, a grande novidade é a publicação integral das notas de leitura feitas por Weber entre dezembro de 1902 e janeiro de 1903 num hotel nas proximidades de Gênova, os chamados "Manuscritos de Nervi”. Parte deste manuscrito foi previamente publicado em inglês por H. H. Bruun e Sam Whimster (Weber, 2012, p.413-418), mas é sem dúvida interessante para os interessados ler as anotações feitas Weber enquanto preparava o tratado "Roscher e Knies e os problemas lógicos de economia política histórica” (p.41-101; p.243-379). Numa de suas anotações, Weber se contrapõe secamente ao conhecido verso de Schiller: "A história não é o tribunal do mundo" (p.627). Fica evidente o considerável esforço desprendido por ele na leitura de $O$ domínio da palavra, um inusual livro escrito por Friedrich Gottl (p.628-637); e assim por diante.

Com isso se chega à segunda e decisiva questão, a mesma questão colocada anos atrás por Wilhelm Hennis (Hennis, 2003, p.75): em que medida apuro filológico e algum material inédito nos permitem revisitar, com outros olhos, a metodologia de Weber? A solução salomônica dos editores não nos parece ter agregado muito de substancial nesse particular. Resta-nos, sob este ponto de vista, dar razão ao protesto de Tenbruck evocado mais acima. Até onde chega nosso conhecimento da literatura especializada mais recente, foram os 12 tomos contendo toda a correspondência ativa de Weber entre 1875 e 1920 (num total de 9.032 páginas) que mais claramente contribuíram para abrir novos caminhos para os Weber Studies.

De toda forma, a competente introdução preparada por Gerhard Wagner realiza um indispensável trabalho de contextualização, e a nosso ver acerta ao se contrapor ao senso comum que atribui a Weber um acento demasiadamente "interpretativo". Além de realçar a importância do hoje esquecido Christoph Sigwart, Wagner dá seguimento à tendência recente (Mata, 2014; Wagner e Härpfer, 2015) de se recuperar a importância das ciências naturais para Weber. Sua carreira docente teve 
início no momento em que a fama de Helmholtz e Du Bois-Reymond atingia seu ápice, e seu recurso moderado ao arsenal conceitual das hard sciences contradiz frontalmente os apóstolos da dicotomia radical entre ciências humanas e naturais, e que justamente naquela época começava a se estabelecer na Alemanha. Não parece ter sido menor a atenção que Weber devotou à lei da conservação da energia de Julius Robert Mayer e, em especial, aos estudos do fisiólogo Johannes von Kries sobre as categorias de causalidade e possibilidade. As evidências apresentadas por Wagner (p.18-24) mostram que foi considerável o influxo de Kries na preparação dos "Estudos críticos no campo da lógica das ciências da cultura" (p.384-480).

O ponto alto do volume é decerto o artigo programático "A 'objetividade' do conhecimento na ciência social e na política social" (p.142-234), mais conhecido na literatura especializada como o "ensaio sobre a objetividade". A importância deste texto é dupla. Por um lado, ele permite mapear à perfeição como Weber concebeu A ética protestante e o espírito do capitalismo do ponto de vista do método. De outro, o fato de estudos recentes no campo da epistemologia histórica e teoria da história, como os de Lorraine Daston (2017) e Arthur Alfaix Assis, ${ }^{1}$ continuarem a referenciá-lo - e isso se dá sempre que o polissêmico conceito de "objetividade" é alvo de reflexão consequente - mostram o quanto ainda podemos aprender com ele. $\mathrm{O}$ uso das aspas no título revelam a distância do autor face a todo "objetivismo". Ao mesmo tempo, Weber reconhece a inevitabilidade do recurso do historiador e do cientista social a determinadas ficções heurísticas, ou seja, os conceitos ou "tipos ideais”. Já em 1904, ele admite que a ficcionalidade é parte integrante da ciência da realidade. Mas, fique claro: como um meio, jamais como "destino". A ciência weberiana não persegue apenas um ideal de rigor. Rigor e senso de responsabilidade precisam andar juntos.

No momento em que o obscurantismo político e religioso ameaça pôr abaixo as conquistas de gerações inteiras de pesquisadores

1 ASSIS, Arthur Alfaix. Objectivity. In: KRAGH, Timme; RÜSEN, Jörn; MITTAG, Achim; SATO, Masayuki (eds.) Core Concepts of Historical Thinking (no prelo). 
brasileiros, dando à noção de "desconstrução" as consequências que seus adeptos relutavam em considerar possíveis hors-texte, duas passagens do ensaio sobre a objetividade (p.147; p.154) atestam seu valor duradouro. Concluamos com elas esta breve resenha: "Nenhum ser humano dotado de reflexividade, que age responsavelmente, pode deixar de ponderar sobre os fins e as consequências de seu agir". Weber não endereça esta advertência aos donos do poder; é à comunidade científica que ele se dirige. Pois é ela, e sobretudo ela, que põe tudo a perder quando se esquece de que "em parte alguma o interesse da ciência é mais intensamente prejudicado, no longo prazo, do que naquelas circunstâncias em que não se quer ver os fatos incômodos e as realidades da vida em sua dureza".

\section{REFERÊNCIAS BIBLIOGRÁFICAS}

DASTON, Lorraine. Historicidade e objetividade. São Paulo: LiberArs, 2017. HENNIS, Wilhelm. Im langen Schatten einer Edition. Zum Erscheinen des ersten Bandes der Max-Weber-Gesamtausgabe. In: HENNIS, Wilhelm. Max Weber und Thukydides. Tübingen: Mohr Siebeck, 2003.

MATA, Sérgio da. Max Weber e as ciências naturais. Ciência Hoje, v. 320, p.22-25, 2014.

MATA, Sérgio da. Realism and Reality in Max Weber. In: HANKE, Edith; SCAFF, Lawrence; WHIMSTER, Sam (eds.) The Oxford Handbook of Max Weber. London: Oxford University Press, 2019.

SELL, Carlos. Resenha de Verstehende Soziologie und Werturteilsfreiheit. Schriften und Reden 1908-1917. Tempo Social, v. 30, n. 3, p.321-334, 2018. TENBRUCK, Friedrich. Abschied von der "Wissenschaftslehre"? In: WEISS, Johannes (Hrsg.) Max Weber heute. Erträge und Probleme der Forchung. Frankfurt am Main: Suhrkamp, 1989.

WAGNER, Gerhard; HÄRPFER, Claudius. Max Weber und die Naturwissenschaften. Zyklos: Jahrbuch für Theorie und Geschichte der Soziologie, v. 1, p.169-194, 2015.

WEBER, Max. Metodologia das ciências sociais. São Paulo/Campinas: Cortez/Unicamp, 2001.

WEBER, Max. Collected Methodological Writings. London: Routledge, 2012. 